\title{
RETRACTED ARTICLE: Homeopathy combat against coronavirus disease (Covid-19)
}

\author{
D. Kalliantas ${ }^{1,2} \cdot$ M. Kallianta ${ }^{3} \cdot$ Ch. S. Karagianni ${ }^{1}$
}

Received: 17 April 2020 / Accepted: 7 May 2020 / Published online: 3 August 2020

(C) Springer-Verlag GmbH Germany, part of Springer Nature 2020

The Editor-in-Chief has retracted this article [1]. Post publication peer review identified the lack of empirical data and the lack of testing of the proposed model as a severe limitation that invalidates the conclusions drawn in the article. The conclusion that epidemiological studies are needed to evaluate homeopathic treatment are not justified based on the model developed by the authors. The simplified approach provided by the authors is not appropriate to model the complex biological associations and not based on evidence-based health research principles.

The authors disagree with this retraction.

The online version of this article contains the full text of the retracted article as Supplementary Information.

\section{References}

1. Kalliantas, D., Kallianta, M. \& Karagianni, C.S. Homeopathy combat against coronavirus disease (Covid-19). J Public Health (Berl.) (2020). https://doi.org/10.1007/s10389-020-01305-Z

Electronic supplementary material The online version of this article (https://doi.org/10.1007/s10389-020-01305-z) contains supplementary material, which is available to authorized users.

\footnotetext{
D. Kalliantas

dimitris@kalliadas.com

1 Department of Materials Science and Engineering, School of Chemical Engineering, NTUA, GR15780, Athens, Greece

2 National Technical University of Athens, 9 Heroon Polytechniou Str. Zografos Campus, 15780 Athens, Greece

3 School of Dentistry, National and Kapodistrian University of Athens, Athens, Greece
} 